\title{
Webseries y series de tv: idas y venidas. Narraciones en tránsito
}

\author{
François JosT* \\ frjost@club-internet.fr \\ Traduccion de Julia Sabina Gutiérrez
}

(Abstracts y palabras clave al final del artículo)

Enviado: 20 de abril de 2013

Evaluado: 19 de junio de 2013

Aceptado: 18 de julio de 2013

Cuando los narratólogos se interesaron por el cine existía la idea, compartida y muy extendida, de que era posible definir los grandes conceptos del análisis del relato, como había hecho anteriormente la teoría literaria e, igualmente, observar los cánones estéticos de una época para mejor sacar a la luz sus características y diferencias. Los estudios sobre la televisión no tuvieron esta suerte: frente a la posible multiplicación de los documentos que se emiten -noticias, variedades, ficción, directos, películas, etc.- hemos debido situarnos en un nivel superior al del texto audiovisual e interrogarnos sobre la lógica subyacente a la estructura y la dinámica de los géneros. Quien quiera estudiar las webseries se encuentra inmediatamente frente a la segunda situación: sólo se puede practicar una lectura «en picado», como decía Barthes, es decir, navegar con los resultados que nos proporcionan los navegadores como Google, por ejemplo. Enfrentarse con problemas de duración -de entre uno y casi 30 minutos (nada que ver con la norma de $1 \mathrm{~h} 30$ ' para las películas o de 52 minutos para la ficción televisiva)-, de narración y de medios técnicos (algunos son muy «amateurs», otros son elaborados por profesionales), de tono (de serio a lúdico), ¿cómo construir un discurso con intenciones generalistas ante un paisaje como éste?

Me he interrogado sobre esta cuestión al abordar las series de televisión. Porque, incluso admitiendo, un poco rápidamente, que todas ellas pertenecen a la ficción (esta cuestión es en realidad más complicada), la heterogeneidad es igualmente amplia. Incluso reduciéndolas a una zona geográfica o a una época, ¿cómo hablar de las series americanas en general o, peor, de series «europeas», como estamos haciendo cada vez más. Frente a esta dificultad para construir un corpus, existen dos formas de proceder: o reunimos arbitrariamente algunas series que nos gustan y en las que encontramos a priori algunos puntos en común- por ejemplo recogemos series que hablen de la prisión y las reagrupamos: Oz, Prison Break, Lockup, etc. ; o no nos

\footnotetext{
* François Jost es profesor de Análisis de televisión y de Semiología audiovisual en la universidad Sorbonne Nouvelle Paris III.
} 
planteamos esta cuestión y nos movemos en función de nuestro propio gusto, lo que es la solución normalmente más adoptada por los universitarios que trabajan sobre las series. En De quoi les séries américaines sont-elles le symptôme? (Jost, 2011), he tomado una tercera vía: coger como punto de partida las series más populares, las más vistas, para entender qué es lo que nos dicen del público que las sigue. Para abordar la cuestión de las webseries, propondría un método del mismo género: elaborar un corpus con las 10 webseries más vistas en Dailymotion en Francia en Enero de 2013 (que es por otra parte la misma que el mes anterior) ; encontrar los criterios que permiten hacer una tipología susceptible de tratar un corpus más amplio, sometiéndola por lo tanto a tests de falsabilidad para la integración de excepciones. Después de esta primera aproximación macrogenérica, utilizaría una nueva prueba de diferenciación tomando en cuenta los géneros de los discursos audiovisuales para preguntarme finalmente de qué manera cambia la recepción de las webseries el sitio web en el que se encuentran albergadas: ¿vemos de la misma manera una serie en el sitio web de un productor y en una cadena de televisión?

\title{
¿QUÉ TIPO DE INTERPRETACIÓN PARA LAS WEBSERIES?
}

A continuación exponemos las 10 series más vistas en Francia en enero de 2013:

\author{
1/ Le Visiteur du Futur : 3432865 \\ 2/ Hello Geekette : 2392478 \\ 3/ J'ai jamais su dire non : 1854378 \\ 4/ Flander's Compagny : 1404567 \\ 5/ DRH : 1241795 \\ 6/ Noob : 1067578 \\ 7/ Limite limite : 990378 \\ 8/ The world of Jean Pierre : 958467 \\ 9/ le Puzzle : 920478 \\ 10/ Zimlo : 824520
}

La primera cuestión que llama la atención al leer esta lista, es que todas las webseries son francesas, lo que puede parecer evidente, dado que estamos en un sitio francés, pero que, reflexionando, es bastante sorprendente. En principio, porque lo que se repite de todas las maneras posibles es que una de las rupturas introducidas por la web es la desterritorialización; luego, porque Francia es uno de los pocos paí- 
ses europeos donde las series americanas tiene masivamente más éxito que las series nacionales; finalmente, porque sabemos que muchos jóvenes internautas descargan las series de televisión americanas en su ordenador en cuanto son difundidas en EE.UU. De hecho, esta preferencia nacional debe interpretarse como un síntoma de un estatus cultural que atribuimos a las webseries: para muchos internautas, las webseries son vistas como una alternativa a la televisión. Se encuentran en el corazón de una lucha intermedial en la que Internet está legitimada como una fuente más pertinente que la televisión, lo que no impide que los defensores de las webseries aspiren a que reemplacen a las series de televisión actuales. Exponemos como testimonio estos comentarios entresacados de los fans:

«Sinceramente, he descubierto Le Visiteur du Futur recientemente, totalmente al azar y estoy sorprendido por la calidad de la serie (mejor que gran cantidad de lo que podemos ver en la televisión francesa según mi gusto, no solamente en el nivel de la interpretación de los actores sino también en el guion y la puesta en escena general...).» (Naerys)

"iiVivan las webseries francesas!! Son mejores que lo que se encuentra en la televisión.» (Jay-Jay du 69)

Dejemos este aspecto de la lucha intermedial de lado (sobre el que insistiré más tarde) y volvamos a la cuestión inicial: ¿Cómo categorizar las primeras 10 webseries? A priori, la etiqueta «web-serie» contiene implícitamente la idea de que están todas del lado de la ficción, en oposición a las producciones etiquetadas como «webdocumentales». De todas formas, como he podido demostrar con respecto a los dibujos animados (Chambat-Houillon/ Jost, 2003; Jost, 2005), podemos considerar que la ficción está estructurada en tres dominantes que corresponden a ejes de mundos televisivos que he distinguido como:

- las ficciones «naturalizadoras», es decir, aquellas que intentan reducir la distancia con el espectador mimetizando lo más posible las situaciones del mundo real y su apariencia física;

- las ficciones «abiertamente ficcionales», aquellas que se desarrollan en un mundo maravilloso o en mundo futuro, como la ciencia ficción;

- Las ficciones «lúdicas», que no son más que pretextos para jugar con las convenciones de los dibujos animados (Tex Avery) o para poner en escena «atracciones». Situaríamos en esta categoría sin ninguna dificultad lo que Jullier denomina como cine "postmoderno", vertiginoso como un carrusel (Jullier, 1997).

Podemos representar este esquema de semiosis indefinida, al estilo de Peirce en su espíritu, aunque no en su letra, de la forma siguiente: 


\section{Monde ludique}

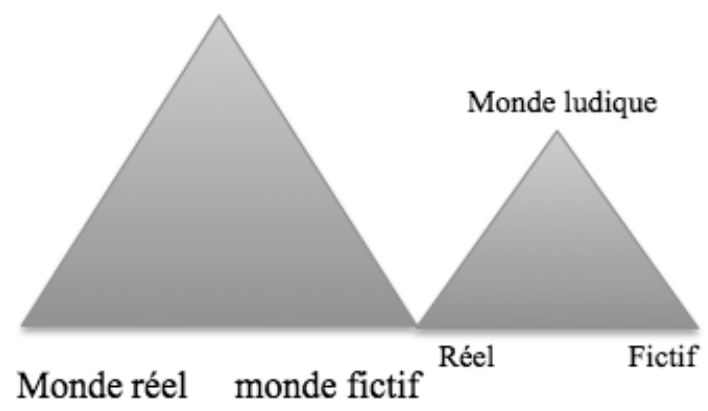

Si utilizamos el triángulo de la derecha, es decir, el que permite alzar la cartografía de los programas de ficción, podemos hacer una primera clasificación de nuestro corpus. En esta distinguimos:

- Las que aspiran a ser series abiertamente de ficción, como Flander's Company, Le Visiteur du futur, Noob, Le Puzzle. Según su sitio web, «la Flander's Company contrata, forma y asegura apoyo logístico y moral a lo mejor de los Supervillanos de hoy y de mañana»; Le Visiteur du futur, como su propio nombre indica, es la historia de un hombre que viene del futuro para impedir que algunos acontecimientos se produzcan, ya que provocarían el fin del mundo; Noob, apodo de los debutantes en los videojuegos, se sitúa en el universo de los «mmorpg» (Massively Multiplayer Online Role Playing Games) y Le Puzzle cuenta las aventuras de dos jóvenes en busca de una pieza perdida en un puzzle de 9 piezas. Aunque se sitúen en el mundo cotidiano, que es una especie de obligación ya que son rodajes con poco dinero, las diégesis de estas webseries tienen todas un componente de ciencia ficción o lúdico, poniendo en juego a héroes de ficción (los «supervillanos») o a videojuegos. Además, muchas de ellas son seriales.

- Aquellas que juegan con situaciones cotidianas y que presentan ficciones «realistas», es decir, ficciones que tienen un anclaje fuerte en el día a día: Hello Geekette pone en escena a dos compañeros de piso - una joven friki, «geek», y un joven que no lo es - y que viven diversas aventuras que giran en torno a pantallas de ordenador o de televisión. J'ai jamais su dire non cuenta la historia de un joven que no sabe negarse y que se deja invadir por un compañero de piso molesto (tomamos en cuenta de paso que se trata del mismo equipo de Le Voyageur du futur). Este modo de narración, sobre el que volveré más adelante, está próximo a ciertos shortcoms como Scènes de ménages o Nos chers voisins en TF1. Esta unidad de lugar puede desplazarse hacia el despacho, 
como en el caso de DRH o Les Opérateurs, que encuentran su inspiración en los despidos y los ERE's.

- Aquellas que están próximas a los sketches o a las bromas visuales como Limite-limite. Se trata de una serie autoconclusiva y no de un serial, de un solo minuto, que promete, como indica su sitio de Internet, «todos los lunes, una broma en imágenes en Dailymotion y Facebook».

El reparto de este top ten en el mapa de los mundos es por lo tanto más o menos el siguiente:

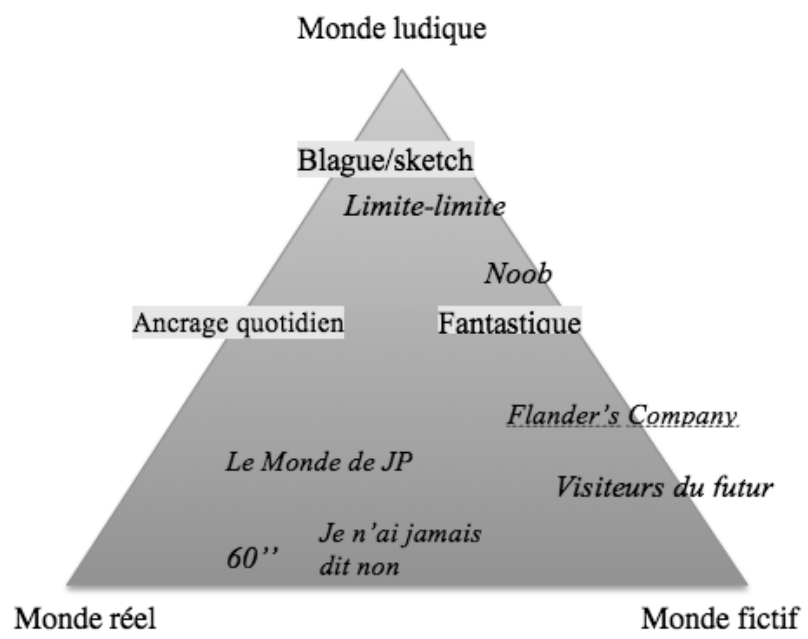

Zimlo, que no es propiamente una serie sino la web del «rapero más viejo de Francia», no figura en este mapa.

Queda The World of Jean-Pierre, que tiene en común con las webseries ancladas en el día a día el poner en escena a un joven en su casa delante del ordenador, donde contemplamos a otro joven delante de su ordenador. Esta situación de enunciación que se produce como un espejo, con el internauta delante de la pantalla, es una situación bastante frecuente, a menudo es un personaje que se dirige a su webcam (60 secondes), de Lonely girl 15 o de Chroniques d'une mère indigne ${ }^{1}$.

Estos cuatro tipos, aunque haya diferencias internas en cada grupo, no toman prestados modelos que son propios de la web, como quieren hacer pensar todos los discursos sobre las innovaciones en la narración en la época digital, sino modelos diversos.

1 Cf. Jean Châteauvert, Les séries web de fiction. Interpeller, Nouvelles vues, http://web-sériew.nouvellesvues.ulaval.ca/futur-numero/numero-13-hiver-printemps-2012/le-cinema-quebecois-et-les-autres-artsdirige-par-elspeth-tulloch/articles/les-series-web-de-fiction-interpeller-par-jean-chateauvert/ 
- Las webseries abiertamente de ficción buscan sus modelos en las películas o en las series, jugando con sus códigos, pero recorriendo al mismo tiempo todas la reglas de la sintaxis cinematográfica (raccords de mirada, ley de los $180^{\circ}$, demarcación de las secuencias, etc.), todo esto recurriendo a múltiples efectos especiales, concretamente para hacer aparecer o desparecer a los personajes... como hacía Méliès. Le Visiteur du futur tiene como modelo explícito la serie Kaamelott, una serie de éxito que ocurre en la Edad Media: ambas comparten la misma forma de interpretación irónica y las mismas gracias fundadas sobre los anacronismos. Esta relación se asume hasta tal punto que uno de los actores de la serie televisiva, Simon Astier, ha aparecido en la tercera temporada de Visiteur du futur.

- Las series ancladas en la vida cotidiana privilegian el modelo teatral y la configuración sistemática de la escena, con su unidad espacio-temporal. Comparten esta característica con las sitcoms y, de hecho, son las únicas que merecen el nombre de «shortcoms». Pero sobre todo la comparten con los numerosos programas cortos que han aparecido en la última década en las pantallas televisivas, ya sea con la puesta en escena frontal de las parejas que se confiesan en Scènes de ménages o con la de vecinos que se encuentran en el rellano de la escalera. (Nos chers voisins). Esta puesta en escena es de alguna manera el mínimo común denominador entre la webserie y la televisión, una especie de esclusa que permite muy fácilmente pasar de una a otra. Uno no se sorprende de que, vista esta familiaridad, Hello Geekette haya pasado en 2009 en TF1 en la emisión Watcast.

- Las bromas o sketchs son también escenas que toman prestada su puesta en escena simplista de la televisión de los orígenes.

- En cuanto a las webseries que desvelan la situación de enunciación del usuario de Internet, éstas descienden directamente de la webcam, son por tanto las únicas que vienen directamente del dispositivo o de las herramientas utilizadas por los internautas.

Cada una de estas contaminaciones discursivas merecería una profundización, que no puedo hacer en el cuadro muy limitado de este artículo. Me limitaré a analizar Visiteur du futur, cuya duración (durante tres temporadas), evoluciones narrativas y recorrido mediático permiten abarcar algunos aspectos de la lucha intermedial entre web y televisión y su mecanismo de legitimación recíproca. Esta serie, en efecto, ha sido fabricada por un joven realizador de publicidad y guionista de televisión, François Descraques, en 2009 y emitida del 27 de abril 2009 al 19 de marzo de 2010. Ante este éxito, que se cuenta en millones de visitas, la cadena de Internet No life la emite a partir del 2 de abril de 2010. La segunda temporada está anunciada el 4 de Julio en la Japan Expo, precedida por reportajes sobre su autor emitidos en el Comic Con. La tercera temporada está producida por un productor y es finalmente puesta en línea por Studio 4, el sitio web de la televisión pública France 4, que va a confiar a François Descraques la realización de una nueva serie, Les Opérateurs.

Debido a que ha emigrado de la red a una cadena pública de televisión, esta webserie es un objeto heurístico ideal para precisar el funcionamiento de «una fícción 
abiertamente ficticia de la web» y para observar los índices de los medios sobre el género o, sobre todo, los géneros discursivos que ha movilizado.

\section{DE LA RED A LA TELEVISIÓN: EL EJEMPLO DE LE VISITEUR DU FUTUR}

\section{DE LA MÍMESIS A LA DIÉGESIS}

El realizador de Visiteur du futur recuerda que al principio se trataba de «tres sketches autónomos» creados bajo el pitch: «un visitante del futuro que llega a la vida de un joven de hoy en día para anunciarle que será, por una acción completamente anodina, el elemento engendrador del fin del mundo.» (Lebathi, 2010: 265). Después ha decidido añadir una intriga «ahí donde la televisión me habría impuesto cien veces el mismo sketch». Aunque el autor sólo ve entre la webserie y la serie televisiva una diferencia de programación, estoy tentado de ver un deslizamiento discursivo: pasando del sketch a la intriga, Le visiteur du futur se traslada de hecho del mundo del espectáculo, con sus formas escénicas televisivas, al mundo de la ficción. Dicho de una forma más narratológica, pasamos de la mímesis a la diégesis o, si lo preferimos, del showing al telling, o, incluso, de la mostración a la narración. En los tres primeros episodios la forma sintagmática es la escena, es decir, esta consecución única de acontecimientos sin hiatos temporales -si no hablamos de las imágenes como flashes que son, según parece, prolepsis, saltos en el futuro, que no afectan de ninguna manera la continuidad de la forma teatral. El paso a la intriga desde el episodio 4 mezcla el mismo principio de predicción causal («esto es lo que va a pasar» si comes un bocadillo), pero se desarrolla en distintos emplazamientos que recorren, en su persecución, el visitante y el joven. Y si recordamos el rol fundamental de la persecución en el paso de la mostración a la narración en el cine de los primeros tiempos (Burch, 1983; Gaudreault, 1988), estaremos tentados de decir que ante la serialidad, teniendo que inventar una continuidad, esta web serie revive la invención del cine. Esta primera mutación de la webserie clarifica la afirmación de Descraques según la cual «entre la webserie y la serie televisiva existen diferencias en los medios técnicos de producción» (ibid: 264). Hacer una serie no puede consistir en quedarse en la demostración, como hacen por ejemplo las series ancladas en lo cotidiano, es hacer narración. En el décimosexto episodio, el relato romperá por primera vez la concatenación cronológica de las secuencias para recurrir al montaje paralelo, otra ruptura histórica del relato cinematográfico normalmente atribuida a Griffith... De tal manera que podemos ver Le Visiteur du Futur como una novela de aprendizaje del lenguaje cinematográfico.... Comprobaremos cómo a medida que los episodios avanzan el realizador introducirá poco a poco una iluminación artificial (como en el cine en el que se ha pasado de la iluminación natural a la electricidad), a ángulos raros o a encuadres trabajados. Después de eso, el relato aborda convenciones del cine: por ejemplo, la «convención que consiste en que el ancestro de un personaje es siempre interpretado por el mismo personaje, pero ataviado con un falso bigote y un sombrero» (ibid: 267). 


\section{LA INVERSIÓN DE LA JERARQUÍA IMAGEN-SONIDO}

Aunque los insertos agujereen la intervención del visitante del futuro, se trata en principio de un relato de palabras, y este relato es el que genera las imágenes. Sería difícil comprender el montaje de las secuencias sin tener en cuenta la relación directa de la palabra y la imagen. Contrariamente a la clasificación del montaje clásico elaborada por Metz, que es una Gran Sintagmática de la banda de imágenes, y que parte por lo tanto de la idea de que la imagen es prioritaria en la construcción de sentido (idea por otro lado discutible), en las webseries, por lo general, el encadenamiento de los planos sólo es comprensible si nos dejamos guiar por la voz. Este montaje existía ya en Amélie (Jeunet, 2001), donde una de las primeras secuencias estaba montada en función de la oposición paradigmática «me gusta/no me gusta». Pero también lo encontramos en una serie televisiva como Bref (emitida por Canal+ [Francia] en 2011). En resumen, la serie es ante todo oral. Pero no a la manera de una voz en off que lanza un relato que la imagen completa o que comentan las imágenes, sino más bien a la manera de una argumentación verbal que reposa en una continuidad de causalidad de apariencia lógica y que desemboca en un resultado absurdo según el conocido efecto mariposa.

Otro síntoma de esta inversión jerárquica del sonido y la imagen es el rol mayor atribuido a los efectos sonoros, que subrayan las apariciones o las desapariciones y que contribuyen a que tengan un aspecto técnicamente aceptable.

\section{LA PERSISTENCIA DEL ESQUEMA NARRATIVO MEDIEVAL}

Más allá de las referencias a la Ciencia Ficción (en concreto a Regreso al futuro), lo que llama la atención en las series de éxito como Le visiteur du futur, es que estas se desarrollan abiertamente a partir de un esquema de actantes seguido al pie de la letra, como James Bond, desde hace tiempo, o como los videojuegos, más recientemente: encontramos aquí un sujeto venido desde lejos, una misión o búsqueda que debe finalizar, opositores y coadyuvantes bien construidos (en el episodio 16, se habla además con humor en los diálogos de la llegada del «elemento perturbador»). Es cierto, algunos personajes se desdoblan -los que parecen amigos se transforman a veces en enemigos-, pero no hay en ello nada que sea desconcertante: dejando de lado la presencia de dobles, las películas más clásicas de espionaje juegan también con los engaños de la apariencia. Las referencias a Kaamelott no están ahí por casualidad: la construcción de Le visiteur de Futur se apoya sobre un esquema medieval, que ha llegado a ser por otro lado una especie de topos: salvar el mundo se ha convertido en una misión casi obligada de los protagonistas en las series que se dirigen a un público joven. La presencia del actor Simon Astier nos orienta hacia otra clase de yacimientos narrativos que van no obstante en este mismo sentido. Él es también el autor de una serie de televisión de una pequeña cadena por cable, Comédie+, Hero corp, que cuenta la creación de una agencia que reagrupa a los superhéroes con el fin de mantener un clima de paz, hasta la llegada de un supervillano, The Lord, que rompe el equilibrio narrativo. Flander's Company, que figura también en el top ten, parte explícitamente de esta base. ¿Es preciso concluir que 
las webseries de éxito giran alrededor de una gran pobreza de temas o, por decir las cosas más factualmente, de una gran economía narrativa, común a la vez a los relatos producidos en la red y a las cadenas destinadas a los jóvenes? No creo que sea una exageración sostener esto.

Lo que llama la atención, por otro lado, al leer los comentarios asociados a la difusión de los episodios de Le Visiteur du Futur en la red, es la cantidad de internautas que se posicionan abiertamente como guardianes de la coherencia de la ficción. Aunque la causalidad de los acontecimientos pueda parecer en algunos momentos delirante, aunque el juego con las paradojas temporales sea una especie de pastiche de los estereotipos sobre la Ciencia Ficción, siempre hay un fan que intenta desembrollar esto:

«Pero lo que es realmente fuerte, es que es realmente realista. Como que al final no llegan a salvar el mundo y no hacen otra cosa que equivocarse». JayJay du 69 en relación al episodio La Crise.

«No lo entiendo. ¿Cómo Judith puede tener una idea de que los Lombardi quieren matar al doctor? ¿Esa misma tarde? Ella se marcha del grupo cuando todo el mundo piensa que ellos cuentan con atacar más 'tarde'. Es una pena, quizá ha sido voluntario y quizás sea explicado más tarde pero me molesta de momento y me impide apreciar el resto» Beltaranis, en relación al episodio 13 de la segunda temporada.

«Pero, ¿por qué tiene todavía sangre en la cara? Aún así me parece genial». Papillon-des-étoiles, a propósito del episodio 1 de la tercera temporada.

«La mejor serie del año, casi sin defectos, digo que casi, porque estaría bien que el viajero del futuro se limpie un poco la cara porque al final de 3 temporadas ya no hay razones para que todavía esté manchado de sangre coagulada desde hace 3 años» nadfri, ibid.

«Sin embargo un detalle que yo no creía posible: ¿cómo los Misioneros pueden ir a la época del Visitante? Pensaba que vendrían de su pasado y la máquina no permite normalmente ir de un futuro a su creación» Cleever, sobre el episodio 4 de la tercera temporada.

«Para responder a Cleever, aparentemente los misioneros vienen de la misma época que el visitante ya que Joseph y él se han encontrado en la prisión necrófila donde también ha encontrado a Henry poco antes de inventar la máquina de viajar en el tiempo. Pero si no hubiese sido este el caso, hay siempre un medio de esperar al visitante gracias a su «doble del futuro»»». ONC32 sobre el episodio 4 de la tercera temporada.

Mientras el maquillaje del visitante del futuro no pretende ningún realismo y es más próximo al cómic, como los paneles que dicen «peligro detrás de ti» que surgen en ocasiones, las reacciones de Papillon-des-étoiles y de Nadfri son literales, serias. En el episodio siguiente, el realizador toma en cuenta estas indicaciones y la cara tiene menos sangre. Cuanto más avanza la serie, la indecisión entre el primer y el segundo grado se hace patente, como si, para pasar por la televisión se necesitara ir hacia un relato «bien hecho», preocupados por la coherencia narrativa y no dejando 
ningún lugar a nuevas narraciones menos preocupadas por la verosimilitud. El realizador reconocerá por otro lado que: «los internautas toman la webserie demasiado en serio, ¡más que nosotros!» (ibid: 273).

A medida que los episodios avanzan, la gramática cinematográfica se hace más clásica, en el sentido de que esta recurre a construcciones secuenciales totalmente icónicas, como si el acceso al mundo televisivo fuese otorgado a aquellos que conocen la lengua canónica. Esta hipótesis es por otro lado confirmada a través de la realización de Opérateurs, webserie de Descarques financiada por France 4. La serie cuenta la historia de un joven que entra en una multinacional donde los comportamientos son incomprensibles y extraños. Aunque la atmósfera pueda parecer opresiva y kafkiana, la puesta en escena es muy poco desconcertante, basada en planos y contraplanos y un découpage analítico. Aunque esté producida por una productora llamada «Nuevas escrituras», la diferencia entre esta webserie y las que conocemos viene más de propiedades del mundo diegético que de la escritura audiovisual en sí misma. Uno de los internautas dice sobre Descraques que «Eres para mi gusto el nuevo Godard del S.XXI», al que otro internauta responde más lúcidamente «bueno, sinceramente, creo que François sería mejor el J.J. Abrams francés o el Steven Spielberg francés que el nuevo Godard del S.XXI» (último episodio de la segunda temporada). Un modelo hollywoodiense o televisivo más que una referencia al inventor de un nuevo lenguaje.

Lo que subsiste finalmente de Le Visiteur de Futur de los orígenes es un cierto tono y una forma de interpretar algo alejada del naturalismo, que flirtea con una cierta ironía. Por lo demás, la serie televisiva es antropófaga, en el sentido que Andrade da a este término, devora a los que intentan hacerle la competencia. Este fenómeno se observa en el otro gran modelo de producción de las webseries, que se apoya en el sponsor de una marca. Este fue el caso de The Cell, producida por una compañía de teléfonos, y hoy en día de Cybergeddon financiado por el antivirus Norton. Realizado por el creador de CSI, Anthony E. Zuiker, esta webserie continúa en la red la retórica de las series televisivas. Del lado de la autoproducción como del lado de la sponsorización, webseries y series acaban por tanto encontrando un terreno común, diferente en los dos casos pero caracterizado por una estética común. Podemos formular la hipótesis de que lo que distingue a estos dos modelos es que las series autoproducidas guardan un tono irónico toda su vida, mientras que las segundas son «serias» de principio a fin. Este argumento de otro tono es por otro lado lo que es destacado por numerosas series: tanto Hello Geekette, que promete ser «la única serie que no veréis en la tele», como Limite-limite, que traspasa las fronteras de lo políticamente correcto. Sin embargo, el ejemplo de Le Visiteur du Futur sugiere que en su aproximación a la televisión las serie autoproducidas se toman más en serio, pierden su ironía, lo que crea conflictos con sus fans. «Si usted colocara su cursor un poco más al lado de lo serio, caeríamos menos en las críticas y si usted lo sacara en el cine pagaría por ir a verlo. Y además, lo que mola es descubrir que el Visitante del futuro sabe combatir!!! 1000 bravos», dice bratislabat en la tercera temporada, que ha sido financiada por el CNC... Esta es la última etapa de legitimación, la película. François Descraques prepara en estos momentos Le sanglot des arbres. Un largometraje. 


\section{SOBRE LA IMPORTANCIA DEL SITIO WEB DE DIFUSIÓN EN LA CONS- TRUCCIÓN DEL SENTIDO}

Acabamos de ver cómo el paso de Internet a la televisión o de la televisión a Internet desemboca en la construcción de terrenos comunes o de intercambios que pueden producirse en los dos sentidos. ¿Qué ocurre en el caso de las webseries que reproducen como en un espejo el dispositivo del usuario frente a su ordenador? Esto es lo que podemos experimentar en Le Monde de Jean-Pierre y 60 secondes.

Le Monde de Jean-Pierre que, recuerdo, pone en escena a un friki delante de su ordenador, atrae comentarios como el siguiente: «es gracioso cómo se parece a lo que yo he vivido: D» (moezthemaster) o «verdaderamente triste ver esto, porque estoy segura de que esto ocurre a las personas que juegan en el ranking WoW o que necesitan 5 o 6 horas de videojuegos al día, de todas formas me veo como era hace 6 meses y es exactamente así» (Olydria). Esta reproducción del dispositivo enunciativo del usuario tiene como efecto la ruptura de la ficción y conlleva una lectura proyectiva que reenvía a la «verdadera vida», al mundo real. Esto es incluso más claro en 60 secondes. Esta ficción producida por la cadena Arte es la primera que se emite en la red todos los días a la misma hora, 19:01 h, en la red social Facebook. Muestra cómo una joven, Fantille, a la que le va tan mal en la oficina como en la vida privada, se dirige a la cámara para contar lo que le ocurre o comentar sus estados de ánimo. El análisis de los comentarios da una idea de los efectos de este dispositivo enunciativo. En primer lugar, nos damos cuenta de que la reproducción de este dispositivo al cual está acostumbrado el internauta, que navega utilizando una webcam o habla con otros gracias a diversos programas como Skype, produce una confusión para algunos: ya no sabemos si se trata de un personaje o de una «persona de verdad». Las referencias que permiten atribuir una identidad a un yo-origen (Hamburger) son aquí confusas, como testimonian estos comentarios cogidos al azar entre muchos otros:

Sandrine Pierre. Creo que debes encontrar un novio para que tu vida sea más trepidante

Adam Fresnais. Fantille, no veo hacia dónde quieres ir... ¿Alternas problemas de trabajo y de sexo?

Cyrille de Lasteyrie. Fantille. Me gusta tu nombre. Me gusta tu estilo.

Gregory Pouy. A mí también me gusta tu nombre.

Manifiestamente, estos internautas consideran a la actriz como una joven que se confía a sus amigos y que se llama realmente «Fantille» y están dispuestos a darle consejos para que mejore su vida. Estas reacciones son interesantes para el semiólogo porque permiten experimentar el papel de muchos parámetros enunciativos. El primero es, evidentemente, la mirada a cámara, que crea inmediatamente, como hemos dicho desde hace tiempo, una intimidad entre el emisor y el destinatario: estos internautas no hablan «de usted» a Fantille, sino que la tutean inmediatamente, integrando la dimensión pseudo-conversacional de la mirada a cámara de la televisión (Jost, 1990). En cuanto al anclaje del yo-origen en lo real, estamos tentados 
de atribuirlo a la posición de la actriz frente a su ordenador. Se trata de un elemento del dispositivo que contribuye a esta posición, pero creo que hace falta añadir aquí otra dimensión, una dimensión pragmática. El hecho de que esta serie esté en Facebook es un factor que la autentifica. Como esta red social es el lugar donde hacemos amigos, la actriz entra en el universo de la «verdadera» vida. Aunque la página de 60 secondes en el sitio Arte contiene pocos comentarios, estos añaden una especie de contraprueba que valida esta hipótesis:

Gigi ¡Muy divertido! Está muy bien escrito, los diálogos son realistas, y la actriz es genial.

Florian Kaleidyscope Pienso que no hay que ver esta webserie como al resto. El concepto es interesante. Fantille (Karine Testa) nos comunica sus sentimientos, pensamientos... y me encanta porque sentimos perfecto su buen (o mal) humor cada día a las 19:01. Después, podemos quererla o no, todo es cuestión de gustos. Yo por mi parte me adhiero en un 500\% .

Hector Lemont Muy malo, mal actuado, mal escrito, un rollo. Pero bueno ARTE intenta hacer cosas, eso está bien ¡continuad!

Mikael No es interesante, ni gracioso, insípido y blando... Karina Testa, que sin embargo es buena actriz, no consigue evitar el naufragio.

La mayoría de los 28 comentarios conciernen al guión, a la interpretación de la actriz, no dudan del estatus del yo-origen ficticio de Fantille. Parece claro que el internauta que va al sitio web de Arte pone una distancia con la webserie, lo que no hace el usuario de Facebook.

De todo esto, podemos concluir que la especificidad de la webserie se encuentra menos en su relato, en su retórica o incluso en los mundos que desarrolla que en el sentido que le otorga el lugar de su difusión, su distribuidor (independiente o portal de Internet). Mientras que las webseries abiertamente de ficción tienen la ambición $\mathrm{y}$, en el mejor de los casos, el destino, de terminar en la televisión, las webseries con dispositivo son objetos mucho más ambiguos capaces de cambiar de sentido en función del lugar de su difusión. Para dar alguna validez a estas conclusiones habría, evidentemente, que ampliar este corpus e incluir otros parámetros como el origen geográfico de la producción o el tipo de autor que realiza las webseries (amateur, profesional aficionado, estudiante de comunicación audiovisual, etc.)

Entre web y televisión se producen procesos de legitimización en un doble sentido: la televisión permanece como una referencia, sea esta un fin en sí mismo o una manera de darse realce y, para las webseries abiertamente ficcionales, la televisión permanece como criterio de éxito, tanto por el tipo de lenguaje como por el lugar de producción. Pero la evolución que conduce de la red al universo televisivo es mucho más compleja de lo que puedo mostrar en este artículo. Antes de llegar a la institución, tiene que ser capaz de crear una comunidad visible por su importancia numérica. Hay que señalar que la webserie pasa por vías alternativas, no únicamente en la red sino también en manifestaciones «reales» donde se encuentran internautas, como en Japan Expo. Pero esta es otra historia. 


\section{BIBLIOGRAFÍA}

Burch, Noël (1983). «Passion, poursuite: la linéarisation». Communications n`38.

Chambat-Houillon, Marie-France, Jost, François (2003), «Padre-hijos: miradas cruzadas sobre los dibujos animados», Comunicación y medios $\mathrm{n}^{\circ} 16$, Santiago, Universidad de Chile, segundo semestre, 2005, 115-124.

Gaudreault, André (1988). Du littéraire au filmique. Klincksieck.

Jost, François (1990). «Un spectateur en quête d'auteur». Degrés n 64, Bruxelles, hiver.

Jost, François (2005). Comprendre la télévision et ses programmes. Armand Colin, coll. 128.

Jost, François (2011). De quoi les séries américaines sont-elles le symptôme? CNRS éditions.

JULLIER, Laurent (1997). L'écran post-moderne, un cinéma de l'allusion et du feu d'artifice. L'Harmattan.

LEBATHI, Yannick (2010). «Ma web-série chérie”, entretien avec François Descraques, réalisateur de la web-série, Le Visiteur du futur», Les Cahiers du CIRCAV n²1, Université de Lille 3.

\section{RESUMEN:}

El artículo estudia las 10 webseries más populares en Francia en enero de 2013, para indagar si las webseries aportan nuevos tipos de relato en relación a las formas breves producidas por las cadenas de televisión. Recurriendo a los interpretantes que son "los mundos" televisivos (Jost), se identifican cuatro grandes tipos de webseries: las webseries abiertamente ficcionales, las series ancladas en la vida cotidiana, las que se emparentan con los sketches $\mathrm{y}$, en fin, las series que juegan con la situación de enunciación. La serie más vista en Francia, Le Visiteur du futur, es objeto a continuación de un análisis detallado, y el autor muestra que entre las series breves de televisión y ciertas webseries se constituye una zona intermedia, una narración en tránsito. En fin, el artículo demuestra que el contexto de difusión -cadena de televisión o emisión en línea en Facebook- modifica la recepción.

Palabras clave: webseries, series televisivas, ficción, narración.

\section{RÉSUMÉ}

Cet article étude les 10 webséries les plus populaires au mois de janvier 2013 en France, pour voir si les webséries apportent de nouveaux types de récit par rapport aux formes brèves qui sont produites par les chaînes de télévision. En recourant aux interprétants que sont «les mondes» télévisuels (Jost), on recense quatre grands types de webséries: les webséries ouvertement fictives, les séries ancrées dans la vie quotidienne, celles qui s'apparentent aux sketches et, enfin, les séries qui jouent sur la situation d'énonciation. La série la plus vue en France, Le Visiteur du futur, fait ensuite l'objet d'une analyse précise et l'auteur montre qu'entre les séries brèves de la télévision et certaines webséries se constitue une zone intermédiaire, une narration en transit. Enfin l'article démontre que le contexte de diffusion -chaîne de télévision ou mise en ligne sur Facebook- modifie la réception.

Mots clé: webséries, séries de télévision, fiction, narration. 